\title{
Austeridade fiscal, autoritarismo e política educacional: as mudanças legislativas na gestão democrática do sistema estadual de ensino e da escola pública de Mato Grosso
}

\section{Fiscal austerity, authoritarianism and educational policy: legislative changes in the democratic management of the school system and the public school of Mato Grosso}

\author{
Marilda de Oliveira Costa* \\ Cassia Domiciano**
}

\begin{abstract}
RESUMO
Este texto analisa parte do mapeamento iniciado em Mato Grosso que modificou a legislação estadual relacionada à gestão democrática da escola pública. Alterações que não encontram terreno fértil em um Estado democrático de direito, mas emergem em um contexto de aprofundamento de medidas neoliberais e neoconservadoras que ganharam espaço, principalmente, a partir de 2016 com o "impeachment", ou golpe de Estado, que retirou a presidenta eleita do executivo nacional. Após tal feito, em nome do emprego, do crescimento e da estabilidade econômica são reproduzidos e ampliados discursos que invocam a revisão constitucional (Emenda 95/2016), reformas trabalhista e previdenciária. Em Mato Grosso (MT), o governador Pedro Taques (2015-2018), do Partido da Social Democracia Brasileira (PSDB), vem desconstruindo os princípios da gestão democrática, garantidos constitucionalmente, por meio de um conjunto de medidas legislativas que os descumprem. O método adotado para análise entrecruza informações do
\end{abstract}

\footnotetext{
* Universidade do Estado de Mato Grosso. Cáceres, Mato Grosso, Brasil. Email: marildacosta532@gmail.com. https://orcid.org/0000-0001-6859-0041.

** Universidade Federal de Mato Grosso. Cuiabá, Mato Grosso, Brasil. E-mail: cassiale@ uol.com.br. https://orcid.org/0000-0003-3030-2416.
} 
período de 2016 a 2018, coletadas em sites oficiais do governo do estado do MT e dados documentais, confrontados com discursos e motivações dos principais atores envolvidos na alteração da política do estado, analisado à luz de referenciais teórico-críticos que abordam o tema Estado, sociedade e educação no contexto de (re)atualização neoliberal. Ao final, discute-se a relação entre a corrosão do princípio constitucional da gestão democrática nas escolas públicas do estado e o retorno mais virulento de velhas e autoritárias formas políticas no país.

Palavras-chave: Neoliberalismo. Gestão democrática. Autoritarismo. Novo Regime Fiscal.

\begin{abstract}
This text presents and analyzes part of the mapping started in Mato Grosso that modified the state legislation related to the democratic management of the public school. Changes that do not find fertile ground in a democratic rule of law, but emerge in a context of deepening neoliberal and neoconservative measures that have gained space, mainly, from 2016 after the impeachment, or coup d'etat, that removed the president. After this, in the name of employment, growth and economic stability, they reproduce and expand discourses that invoke the constitutional revision (Amendment 95/2016), labor and social security reforms. Pedro Taques (2015-2018), governor of the State of Mato Grosso, of the Brazilian Social Democracy Party (PSDB) has been deconstructing the principles of democratic management, guaranteed by the constitution, through a set of legislative measures that disregard them. The method adopted for analysis crosses information from the period 2016 to 2018, collected on official websites of the state of Mato Grosso, and documentary data confronted with discourses and motivations of the main actors involved in the alteration of state politics, analyzed on the bases of reference theoretical-critics that approach the theme State, society and education in the context of neoliberal (re) updating. In the end, we discuss the relationship between the corrosion of the constitutional principle of democratic management in state public schools and the most virulent return of old and authoritarian political forms in the country.
\end{abstract}

Keywords: Neoliberalism. Democratic Management. Authoritarianism. New Tax Regime.

DEMOCRACIA ENCARCERADA

Fecharam o portão!

Interditaram a gestão!

Comunidade escolar ali não entra não!

Nomearam uma interventora 
Como se fosse normal e legal instituir assim uma Diretora,

Por ordem lá da capital!

Pai, mãe, aluno e professor protestaram.

Incrédulos diante do que presenciaram, em alto e bom tom gritaram:

"A escola pública é nossa, e não daqueles que a trancaram e que dela se apossaram!"

Fecharam o portão! Proibiram a entrada!

Cresceu a indignação em ver a democracia encarcerada!

E o movimento se fez na rua e na calçada

Um grito forte se fez ouvir:

Não à intervenção autoritária e tecnocrática!

Que se reestabeleça a Gestão Democrática!

(MACHADO, 2018)

\section{Introdução}

A situação descrita na epígrafe deste texto poderia tratar-se de ficção ou mesmo de uma crítica preventiva sobre um futuro incerto e sombrio que emergiria de oportunismos políticos e falta de apreço à democracia, mas observa-se que eles foram de fato gerados com o golpe de 2016. Antes fosse apenas prenúncio, mas é, de fato, uma denúncia da realidade vivenciada por uma escola pública da rede estadual de ensino de Mato Grosso em 2018.

Há indícios de que essa situação não é um fato isolado na rede, já que desde 2016 a Secretaria Estadual de Educação do Estado determina a prorrogação de mandatos eletivos de diretores escolares, membros de Conselhos Deliberativos, coordenadores pedagógicos e de assessores pedagógicos abrindo precedentes para seu aprofundamento. As prorrogações determinadas pela SEDUC/MT, contrariam a Lei Estadual no 049/1998, a Lei no 7040/1998 e a Lei nº 9241/2009, entre outras, que instituíram a gestão democrática no sistema e na escola pública no estado de Mato Grosso, as quais seguem o estabelecido no Art. 206, inciso VI da Constituição Federal de 1988 e no Art.14 da Lei de Diretrizes e Bases da Educação Nacional, Lei no 9394/96.

1 Este texto foi escrito por Ilma Ferreira Machado, professora da UNEMAT, em junho de 2018, no calor da luta da comunidade escolar de uma escola da rede pública estadual no município de Cáceres - MT que decretara greve pelo direito de eleger o diretor escolar. Após várias mobilizações da comunidade escolar, com apoio de entidades de direitos humanos e alguns professores do Programa de Pós-Graduação em Educação da Universidade Estadual do Estado de Mato Grosso (PPGEDu-UNEMAT), nota de repúdio às ações autoritárias da Secretaria de Estado de Educação (SEDUC), divulgada nos meios de comunicação, reuniões com o Ministério Público Estadual e com a Secretária de Estado da Educação de Mato Grosso, chegou-se a uma resolução do problema e a comunidade pode escolher o diretor. 
Os fatos narrados não se desvinculam de acontecimentos mundiais e nacionais, que marcaram uma agenda regressiva no campo social e na soberania nacional no país após a destituição da Presidenta da República do Brasil por um golpe de Estado em agosto de 2016, como afirmam diversos juristas nacionais e internacionais, intelectuais e cientistas políticos, entre os quais, Souza (2017), Chomsky (2016) e Miguel (2018).

Desde 2016, no Brasil, cresceu muito rapidamente uma onda de reformas neoliberais e neoconservadoras por meio do aprofundamento de diferentes formas de privatização dos serviços prestados pelo Estado que acabaram por conter o pequeno e breve avanço dos direitos sociais brasileiros. A apropriação dos recursos energéticos pelo grande capital nacional e estrangeiro vem se intensificando a passos largos, de modo a maximizar seus lucros, cujo destaque especial pode-se dar ao capital financeiro, confirmando análises de Beck (2015), sobre as guerras atuais por recursos energéticos, e de Escobar (2016) e Korybko (2018) quando apontam o Brasil no epicentro das chamadas guerras híbridas², também denominadas guerras não convencionais, em razão dos acontecimentos dos últimos três anos no país.

Como afirma Streeck (2012, p. 37), é um momento histórico em que buscam-se conter "as sucessivas crises endêmicas do capitalismo [...] como resultado das tensões entre mercados capitalistas e políticas democráticas", conforme ficou evidenciado com as sucessivas crises a partir da década de 1970 e a crise bancária de 2008, gerando a perda de uma estabilidade econômica mínima.

O momento expressa frustações geradas por expectativas depositadas no avanço democrático no país e, por outro lado, tentativas de retorno a um tempo histórico que volta a nos incomodar, com novas roupagens. Essas tentativas foram agravadas após o resultado das eleições de 2018 que ascendeu ao poder Jair Messias Bolsonaro, do Partido Social Liberal (PSL), com perfil ultraconservador e privatista ${ }^{3}$. Venceu um presidente que não escondia sua simpatia pelos anos de chumbo vivenciados no Brasil, mesmo diante de cicatrizes não curadas como pessoas ainda desaparecidas, desigualdades econômicas, culturais,

2 As Guerras Híbridas são conflitos identitários provocados por agentes externos (o exemplo mais emblemático refere-se à atuação dos Estados Unidos em diversos contextos internacionais), que exploram diferenças históricas, étnicas, religiosas, socioeconômicas e geográficas em países de importância geopolítica, por meio da transição gradual das revoluções coloridas para a guerra não convencional. O intuito é desestabilizar, controlar ou influenciar projetos de infraestrutura multipolares por meio de enfraquecimento do regime, troca do regime ou reorganização do regime (KORYBKO, 2018).

3 Após a posse do novo presidente da república em 1 de janeiro de 2019, tornam-se recorrentes nas mídias anúncios de medidas como regulamentação do Homeschooling, privatização de empresas estatais, flexibilização da posse de armas. 
políticas e educacionais não sanadas em razão de o país não passar a limpo a recente Ditadura Civil Militar, que durou oficialmente $21 \operatorname{anos}^{4}$, e ainda atua na promoção de uma democracia formal, em que o político é artificialmente separado do econômico (WOOD, 2003). Nota-se que as estratégias usadas pelo capital para recomposição de taxas extorsivas de lucros sobre o trabalho, sobre as finanças públicas e sobre os direitos sociais levam ao grau zero de legitimidade ${ }^{5}$ do Estado e da frágil democracia brasileira (SANTOS, 2002).

As tensões entre democracia e capitalismo não são recentes, mas o acirramento desse par antitético tem agudizado e tensionado as relações sociais na sociedade brasileira desde o golpe de Estado de 2016. Essas tensões são sentidas em diferentes áreas, e a educação não tem sido poupada. Sérios e profundos ataques, em andamento desde as contrarreformas neoliberais dos anos 1990 no Brasil, direcionam-se à educação, seja pelo mercado, em que empresários viabilizam suas propostas privatistas por meio de Fundações e outras instituições, seja por grupos neoconservadores, como os patronos do movimento "Escola Sem Partido", também presente no estado de Mato Grosso.

Diante desse cenário, com base em levantamentos iniciais de pesquisa em andamento ${ }^{7}$, nosso objetivo principal é examinar medidas legislativas do governo do estado do Mato Grosso, no período de 2015 a 2018, que se relacionam à Meta 19 do Plano Nacional de Educação ${ }^{8}$, ou seja, ações ligadas à efetivação - ou não - da gestão democrática. Deteremos nosso olhar sobre o mínimo de gestão democrática que resta no sistema e na escola pública de Mato Grosso, em razão de reflexos do golpe de Estado de 2016 na esfera estadual.

4 O último período de ditadura militar brasileira ocorreu de 1964 a 1985.

5 Boaventura de Souza Santos afirma que o grau zero de legitimidade do Estado se dá como uma nova forma de fascismo (SANTOS, 2002).

6 O movimento Escola Sem Partido (ESP), fundado pelo advogado e procurador do Estado de São Paulo, Miguel Nagib, prega o combate as ideologias nas escolas, com ênfase à "ideologia" de gênero e sexualidade. O movimento defende a "neutralidade" do ensino. O ESP e seus colaboradores ampliaram sua visibilidade a partir de 2014 quando projetos de leis foram apresentados nas câmaras legislativas requerendo a neutralidade do ensino e a criminalização dos professores que descumprissem as regras propostas. Primeiro o PL é apresentado no Rio de Janeiro pela família Bolsonaro - PL 2974/2014 (estadual)/PL 867/2014 (municipal) e posteriormente em âmbito nacional - PL 7180/2014 e PL 867/2015 - respectivamente pelos deputados, Erivelton Santana, do Partido Social e Cristão (PSC) e Izalci Lucas, do Partido da Social Democracia Brasileira (PSDB) (BRAIT, 2016). Em dezembro de 2018 o projeto fora arquivado, podendo ser reaberto pelos deputados que tomaram posse na legislatura de 2019-2022. A notícia foi veiculada em diferentes jornais e no site da ANDES - Associação Nacional dos Docentes de Ensino Superior (ANDES, 2019).

7 Trata-se de projeto parcialmente financiado pela Fundação de Amparo à Pesquisa do Estado de Mato Grosso (Fapemat), intitulado: O planejamento educacional no estado e municípios matrogrossenses: do plano estadual ao plano municipal de educação. Coordenado pela autora principal.

8 Lei 13.005, de 25 de junho de 2014. 
Para a análise, utilizamos referenciais que abordam aspectos da conjuntura nacional, sua interação com o contexto internacional e os reflexos das medidas neoliberais, adotados com o golpe de Estado de 2016 e materializadas na austeridade fiscal, nas políticas educacionais locais e também nas mais recentes alterações na noção de democracia como direitos sociais e a transição para uma pós-democracia gestionária. Este último aspecto, como adverte Lima (2014), resulta de um contexto no qual:

[...] a educação tem sido objeto de reformas a partir da concepção de um Estado gestionário, supervisor e avaliador, introduzindo-se novas modalidades de governação da educação através de parcerias com o terceiro setor, da instituição de mecanismos de concorrência entre o público e o privado, de gestão centrada nos resultados escolares e numa racionalização das redes escolares, a par de processos de grande deterioração das condições de trabalho nas escolas e de recentralização do poder, motivados por políticas de austeridade e de ajustamento económico [...] (LIMA, 2014, p. 1077).

Para tanto, utilizou-se um método que entrecruza dados coletados em sites da web (oficiais, nacional e local) documentais, confrontados com discursos e motivações dos principais atores envolvidos na implantação da política, bem como o papel reservado a cada sujeito nesse processo.

A gestão democrática, conforme reflexões de Amaral (2018) apresentadas nas considerações iniciais da entrevista $A$ gestão democrática das escolas como referencial político, educativo e simbólico, em que o autor afirma, junto com Licínio Lima, algo que não é estranho a pesquisadores, gestores, professores, pais e estudantes de escolas públicas do país: "a gestão democrática da escola não está dada, não se decreta nem se institui por meio de uma legislação que a regulamente" (AMARAL, 2018, p. 244). Nesse sentido, cabe lembrar que a gestão democrática é uma categoria político-administrativa instituída com a Constituição Federal de 1988 e que sua materialização em escolas públicas do país tem passado por avanços e recuos tal como tem ocorrido no sistema estadual de educação do Mato Grosso. No estado, esse princípio tem sido cerceado, corroído, esgarçado, por medidas legislativas, desde 2016.

Amaral chama a atenção para aspectos e condições objetivas da realidade que possibilitam a materialização de uma escola democrática: "a escola democrática exige estruturas democráticas e existe como processo, com avanços e recuos de demandas, sobretudo, práticas democráticas e participativas nos processos de tomada de decisões”. (AMARAL, 2018, p. 244). 
Para compreender as relações mais recentes das rupturas entre capitalismo e democracia, materializadas no Brasil com o golpe de Estado de 2016, a objetivação das contrarreformas do Governo de Michel Temer do Movimento Democrático Brasileiro (MDB) na esfera estadual e as mudanças legislativas na gestão democrática da escola pública de Mato Grosso aparecem como consequências imediatas do golpe. Este texto está dividido em quatro partes. A primeira apresenta a reorganização da direita neoliberal no Brasil: crise política, golpe de Estado e suas implicações para a democracia; a segunda apresenta os reflexos das rupturas jurídico-políticas e o ajuste fiscal em Mato Grosso; a terceira mapeia e analisa as recentes alterações legislativas na gestão democrática do sistema estadual de ensino e da escola pública de Mato Grosso como resultado de oportunismos políticos de gestores governamentais embalados pelo golpe e a restauração explícita de formas clientelistas, autoritárias e técnicoburocráticas na estrutura social e na educação; na última parte, apresentamos uma síntese da temática, apontando as consequências de medidas autoritárias, como a austeridade fiscal e os Decretos e Portarias, para a gestão democrática do Sistema e das escolas públicas da rede estadual de ensino de Mato Grosso.

\section{Reorganização da direita neoliberal no Brasil: crise política, golpe de Estado e suas implicações para a democracia}

De acordo com Wood (2006), a história da democracia moderna, especialmente nos países centrais, foi inseparável do capitalismo. "Foi o capitalismo que tornou possível uma democracia limitada 'formal' antes que 'substantiva', algo que nunca foi possível antes. E é por isso que o capital pode tolerar algum tipo de democracia" (WOOD, 2006, p. 382). Se nos países de capitalismo central a democracia foi limitada, desenhada nos moldes aceitáveis pelo capital, nos países latino-americanos as expectativas com a democracia geradas com a abertura política dos anos de 1980 foram frustradas (BORON, 2003) por medidas neoliberais de austeridade, incentivadas pelos organismos multilaterais via Consenso de Washington. Tais medidas encontraram terreno fértil nos governos de Collor de Mello (1990-1992) e de Fernando Henrique Cardoso (1995-2002), com a implementação de contrarreformas no campo econômico e social, incluindo o educacional.

Em 2003, Luís Inácio Lula da Silva, do Partido dos Trabalhadores (PT), venceu as eleições para a Presidência da República, com uma plataforma de governo pautada no "compromisso pela produção, pelo emprego e por justiça 
social" . A proposta anunciada, salvo algumas exceções, teve continuidade no primeiro governo da Presidenta Dilma Rousseff (2010-2014); mesmo na contramão da crise do capitalismo global, o período foi marcado pelo crescimento econômico e pela ampliação dos direitos sociais. Já o segundo mandato do governo da Presidenta - 2015-2016 - foi marcado pela polarização do debate político e por políticas de cortes e austeridade fiscal ${ }^{10}$, que visavam a manter o equilíbrio das contas públicas e superávit primário elevado, congruente com os efeitos "tardios" no Brasil da crise financeira do capitalismo global de 2008.

Em linhas gerais, o ajuste fiscal teve como "álibi", a manutenção do equilíbrio das contas públicas, para mostrar às agências internacionais de classificação de "risco" (Standard \& Poors, Moodys e Fitch Ratings, por exemplo) ${ }^{11}$ que o país era "bom pagador", portanto, um local seguro para "investimentos" com alta rentabilidade, especialmente para o rentismo. Este contexto mostra as dificuldades enfrentadas pela sucessora do Presidente Lula da Silva em mudar a política macroeconômica ortodoxa, condicionada pelo neoliberalismo (BRESSER PEREIRA, 2010).

A crise política no Brasil, alavancada por mobilizações ocorridas em 2013 que reivindicavam redução de tarifas no transporte público, logo foi apropriada por outros atores, como a grande mídia e movimentos como Revoltados On-line, Movimento Brasil Livre, Vem pra Rua, etc. O movimento Vem Pra Rua evidenciava a não aceitação do resultado das urnas em 2014, ou seja, a reeleição de Dilma Rousseff. O Movimento Brasil Livre (MBL), financiado por petroleiras americanas, defendia a volta das ideias ortodoxas neoliberais, como a liberalização econômica e a privatização, e criticava o apoio do Estado para as políticas sociais de distribuição de renda; já o grupo dos Revoltosos On-line, composto por maioria de militares, pregava a volta do regime militar (JINKINGS; DORIA; CLETO, 2016).

9 A ideia é o crescimento econômico com distribuição de renda. Carta ao povo brasileiro de Luís Inácio Lula da Silva. (PT, 2018).

10 No dia 30/11/2015, foram anunciados cortes no valor de $\mathrm{R} \$ 10,7$ bilhões no Orçamento da União para 2015. Era o terceiro pacote envolvendo cortes no Orçamento da União no ano de 2015. Em maio do mesmo ano, houve um corte no valor de R \$ 69,9 bilhões; destes, R \$ 9,2 bilhões foram contingenciados na área educacional e R \$11,7 bilhões na área da saúde. As pastas das cidades, saúde e educação foram as mais afetadas por esse último pacote (FOREQUE; CRUZ; VERSIANI, 2015).

11 Empresas de avaliação que atuam sob encomenda do sistema financeiro mundial emitem opiniões sobre a situação fiscal e econômica, entre outras, de papéis, empresas ou países. Vale destacar, porém, que na quebra do mercado imobiliário americano, que esteve no epicentro da crise de confiança global desencadeada em 2008, os papéis do setor que se mostraram "ativos podres" tinham nota máxima das agências de classificação de risco com grau de investimento (GAZETA DO POVO, 2014). 
As mobilizações intensificaram-se entre 2013 e 2016, chegando ao afastamento de Dilma Rousseff ${ }^{12}$ da Presidência da República por meio de processo de impeachment no Senado Federal. Esse processo foi considerado, tanto por inúmeros juristas brasileiros e internacionais, quanto por intelectuais da área de Ciência Política, entre outros, como um pretexto, um golpe para afastar a Presidenta eleita. Por não haver crime de responsabilidade, o impeachment é, de fato, um golpe "brando", afirma Chomsky (2016).

Após o afastamento da Presidenta reeleita, em seu lugar, assumiu o Vice-presidente Michel Temer, do Partido do Movimento Democrático Brasileiro (PMDB), que implementou um novo plano de governo, diferente daquele referendado pelo voto popular. Com o documento Uma ponte para o futuro (2015) $)^{13}$, elaborado pelo seu partido (PMDB), Temer propõe mudanças drásticas nos rumos das políticas econômica e social do Brasil, rompendo com uma sequência de 12 anos de políticas neodesenvolvimentistas dos governos Lula e Dilma, que desenvolviam "um projeto democrático e popular com crescimento econômico, distribuição de renda para o fortalecimento do mercado interno, reduzindo as desigualdades sociais e ampliando as oportunidades dos trabalhadores(as) participarem do mercado de trabalho" (RAMOS; FILHO; LOGUERCIO; FILHO, 2016, p. 24).

Com o pretexto de combater o desemprego, o governo do Presidente Michel Temer (PMDB) promove uma série de contrarreformas que afetam a área social, tais como: limitação dos gastos com a saúde e com a educação

12 No dia 17 de abril de 2016 (votação em um domingo, com direito a transmissão ao vivo pela mídia comercial do país), a Câmara dos Deputados autoriza abertura de processo de impeachment contra a Presidenta Dilma Rousseff. Esta perdeu o mandato em 31 de agosto de 2016, por votação no Senado Federal, fato noticiado nas maiores mídias brasileiras e também no senado notícias (SENADO NOTÍCIAS, 2016).

13 Em resumo, essas mudanças referem-se a: (a) ampliar o superávit primário e reduzir os gastos públicos; (b) estabelecer um limite para as despesas de custeio inferior ao crescimento do Produto Interno Bruto (PIB); (c) assegurar um percentual do PIB para pagamento de dívidas; (d) promover a privatização das áreas de logística e infraestrutura, buscar parcerias para a oferta de serviços públicos e estabelecer concessões na área de petróleo; (e) realizar abertura econômica ao comércio internacional; (f) criar agências reguladoras para responsabilizar os dirigentes de empresas estatais pelos serviços; (g) reformar amplamente o processo de elaboração e execução do orçamento público, tornando o gasto mais transparente, responsável e eficiente; (h) limitar os gastos com políticas públicas sociais; (i) na área trabalhista, permitir que o negociado prevaleça sobre o legislado; (j) simplificar e reduzir os impostos para exportação; (k) diminuir as exigências burocráticas das empresas para concessão de licenciamentos ambientais; (1) dar alta prioridade à pesquisa e ao desenvolvimento tecnológico, que são a base da inovação. Resumo elaborado pelas autoras a partir do documento "Uma ponte para o futuro" (PARTIDO DO MOVIMENTO DEMOCRÁTICO BRASILEIRO, 2015). 
por 20 anos (Emenda Constitucional 95/2016) e interrupção das políticas de valorização do salário mínimo e do servidor público, reforma trabalhista, com a terceirização irrestrita do trabalho em todos os setores de serviços e prevalência do negociado sobre o legislado e alteração na previdência, diminuindo benefícios e aumentando o tempo de trabalho para a aposentadoria. Após ampla mobilização dos trabalhadores e criação de uma Comissão Parlamentar de Inquérito da Previdência (2017) no Senado Federal, concluiu-se pela inexistência de déficit na pasta (BRASIL, 2017). Até janeiro de 2019, essa última medida ainda não fora aprovada na íntegra pelo Congresso Nacional. No entanto, o governo federal vem cortando benefícios de pessoas inaptas ao trabalho por diversos tipos de enfermidades.

A primeira agenda do governo Michel Temer a ser cumprida foi a aprovação do Projeto de Lei de Emenda Constitucional, denominado PEC 241/552016, que instituiu o "Novo Regime Fiscal" para gastos primários, ou seja, saúde, educação e assistência social. A aprovação dessa PEC, transformada em Emenda Constitucional 95, suspendeu, ao menos em nível federal, o caput do Art. $212 \mathrm{CF} / 1988$ por 20 anos, que determinava:

A União aplicará, anualmente, nunca menos de dezoito, e os Estados, o Distrito Federal e os Municípios vinte e cinco por cento, no mínimo, da receita resultante de impostos, compreendida a proveniente de transferências, na manutenção e desenvolvimento do ensino (BRASIL, 1988).

A EC 95/2016,

[...] determina o congelamento das despesas primárias por vinte exercícios financeiros, admitindo-se apenas a correção do total da despesa pelo Índice de Preços ao Consumidor Amplo (IPCA), tomando como referência o exercício financeiro de 2017 (BRASIL, 2016).

A EC 95/2016, aprovada em junho de 2016, criou um novo regime fiscal, congelando por 20 anos os gastos primários, que incluem, saúde, educação, previdência e outras políticas sociais, nos patamares do exercício financeiro de 2017, permitindo apenas a correção do total da despesa pelo Índice de Preços ao Consumidor Amplo (IPCA): 
[...] É importante ressaltar que o congelamento é sobre a despesa primária total; assim, se em alguma área, como a previdência social, por exemplo, o crescimento for acima da inflação medida pelo IPCA, deverá ocorrer uma queda de valor equivalente em outras áreas de atuação do Governo Federal (PINTO, 2018, p. 861).

Na prática, os recursos públicos tornaram-se ainda mais vulneráveis às disputas políticas. Além disso, a economia com o corte em políticas sociais (saúde, educação, previdência, assistência social), que favorece a população mais pobre, ajuda o caixa federal a pagar juros de títulos da "dívida pública" aos banqueiros, com isenções fiscais para os hiper-ricos (SALVADOR, 2016), não bastasse "a Lei no 9.294/95, art.10, que eliminou o Imposto de Renda Retido na Fonte sobre os lucros e dividendos distribuídos para os resultados apurados a partir de 1/01/1996, seja o sócio capitalista residente no país ou no exterior" (SALVADOR, 2016, p. 21).

Um Estudo do Departamento Intersindical de Estatística e Estudos Socioeconômicos (DIEESE), publicado em setembro de 2016, mostra que, se as regras do tal regime fiscal de austeridade proposto pela EC-95 fossem implantadas de 2002 a 2015, os recursos para a educação teriam sofrido uma redução de 47\% e, para a saúde, haveria uma perda de $27 \%$ no mesmo período.

As medidas anteriormente citadas, associadas à EC-95, condenam o cumprimento dos avanços conquistados no atual Plano Nacional de Educação 2014-2024, elaborado durante o governo de Dilma Rousseff (PT), com representações e participação popular da sociedade brasileira, por meio da Conferência Nacional de Educação (CONAE), e posteriormente aprovado pela Câmara e Senado Federal. O Plano Nacional de Educação, sancionado em 25 de junho de 2014 pela Presidenta Dilma, significa grande avanço para a educação no Brasil, mas, conforme o relatório do $2^{\circ}$ ciclo de monitoramento das metas do PNE, divulgado em 06 de junho de 2018 pelo Instituto Nacional de Estudos e Pesquisas Educacionais Anísio Teixeira (INEP), o país cumpriu apenas uma meta do Plano (BRASIL, 2018).

Dentre as metas comprometidas está a 19 e suas oito estratégias, não somente em razão do Novo Regime Fiscal, mas, também, pela onda "moralista" e autoritária que emergiu com o golpe que assola o país, pela inércia da comunidade escolar, pelo desprestígio da profissão docente e pela responsabilização de gestores escolares dentro de um contexto que tem promovido sistematicamente a ascensão de uma pós-democracia gestionária (LIMA, 2014), com o atropelo do PNE por interesses privatistas na área educacional. 


\section{Reflexos da ruptura jurídico-política na esfera estadual: o novo regime fiscal em Mato Grosso}

Mesmo a EC-95/2016 valendo apenas na esfera federal, em Mato Grosso, o governo de José Pedro Taques (2015-2018), do Partido da Social Democracia Brasileira (PSDB), eleito com o slogan "Estado de Transformação", não tardou a alinhar seu discurso ao do governo federal, cujo argumento em defesa do ajuste fiscal era praticamente o mesmo: crise fiscal do Estado decorrente do desequilíbrio das contas públicas, ou seja, de gastos excessivos com políticas sociais e baixa arrecadação ${ }^{14}$.

$\mathrm{O}$ acordo entre governo federal e governos estaduais deu-se em nome da renegociação de dívidas com a União. Mato Grosso não se encaixava nos critérios do governo federal para adesão ao plano de auxílio aos estados em situação fiscal crítica, como argumentavam, à época, sindicalistas do serviço público estadual $~^{15}$. No entanto, voluntariamente, o governo do estado aderiu ao plano de auxílio aos estados e, por meio da Mensagem 67, de 23 de agosto de 2017, enviada à Assembleia Legislativa, propôs projeto de Emenda Constitucional para instituir "Regime de Recuperação Fiscal" (RRF) do estado. Na exposição de motivos, a Mensagem trouxe o seguinte objetivo:

[...]reforçar a disciplina e o equilíbrio fiscal, para um período de dez exercícios financeiros, mediante a criação de regras que evitem a expansão do gasto corrente além da capacidade financeira do Estado. As medidas ora propostas também acompanham as diretrizes orientadoras adotadas pelo governo federal, considerando realidade das contas públicas de Mato Grosso (MATO GROSSO, 2017).

A Assembleia Legislativa acelerou a votação da Proposta de Emenda Constitucional (PEC) 10/2017, conhecida como PEC do teto dos gastos, para cumprir o prazo estabelecido pelo governo federal, de até 30 de novembro de 2017, de modo que os estados aprovassem a proposta e aderissem ao plano

14 Esse governo deu continuidade à política de renúncia fiscal iniciada na década de 1990 com a Lei Kandir e foi aprofundada em 2003 no governo Blairo Maggi (2003 a 2010) (REPÓRTER MT, 2017).

15 Sindicalista afirma que discurso do Governo sobre PEC é "falácia" (AGÊNCIA DA NOTÍCIA, 2017). 
de auxílio que previa maior prazo para quitação das dívidas das unidades da federação com a União.

Inicialmente, a PEC apresentada pelo governo previa um congelamento de gastos por 10 anos. No entanto, com a pressão social, os deputados reduziram o período pela metade do tempo sugerido e aprovaram a PEC em 23 de novembro de 2017. O principal alvo do ajuste fiscal foram os serviços e os servidores públicos estaduais do Executivo, alvo preferido de medidas neoliberais, portanto, privatizantes. O governo ficou proibido de conceder aumento salarial, fazer contratações, realizar concursos públicos ou adotar qualquer ação que gerasse custos não previstos no orçamento anual, pelo prazo de cinco anos. Assim como na esfera federal, em nível local, houve inúmeras ameaças/tentativas da aprovação a reforma da previdência dos servidores do poder público estadual, algo muito contestado pelo movimento sindical e aventado novamente pelo governo recém empossado em janeiro de $2019^{16}$.

$\mathrm{Na}$ área educacional, a gestão do sistema e da escola pública estadual não ficou imune às medidas autoritárias e tecnocráticas do executivo estadual.

\section{Alterações legislativas na gestão democrática do Sistema Estadual de Ensino e da escola pública de Mato Grosso e o oportunismo político de gestores governamentais}

Não por acaso, o substrato material que emergiu do pós-golpe de 2016 revela sérias dificuldades em conviver com um mínimo de democracia formal, incluindo a das instituições educativas, de governos oriundos da "Nova Direita". As lutas democráticas em oposição à ditadura que vigorou por 21 anos (1964 a 1985) somadas à Constituição cidadã, possibilitaram no país uma democracia mais "das formas e dos processos, das regras e do funcionamento

16 O Governo Mauro Mendes do Democratas (DEM) assumiu em 1/01/2019 e com o mesmo discurso de crise do Estado (somente no Executivo) enviou para a Assembleia Legislativa (AL) um "pacotão" com quatro projetos de Lei que compõe o denominado "Pacto por Mato Grosso", contendo temas como reforma administrativa, Fethab, MT Prev e RGA. Dentre as medidas constam extinção de órgãos públicos como a Empresa Mato-Grossesense de Pesquisa, Assistência e Extensão Rural (EMPAER) e da Empresa Mato-Grossense de Tecnologia da Informação (MTI), congelamento de salários e de progressão na carreira dos servidores do Executivo, aumento da alíquota da previdência de 11 para $14 \%$....etc. Estas medidas foram alvo de intensos protestos e mobilização dos servidores públicos em Janeiro, inclusive com a ocupação da AL; os deputados, destes 14 não se reelegeram, interromperam o recesso para votar o chamado "pacote do mal", aprovado em $2^{\text {a }}$ votação na noite do dia 24/01/2019. 
das organizações públicas, da competição interpartidária e de certas formas de participação" do que propriamente da democratização da educação, da cultura, das mentalidades e das relações sociais de todo tipo (LIMA, 2018, p. 246).

As mudanças legislativas na gestão democrática do ensino público produzidas a partir de 2016 podem ser um indício de quão frágil é a democracia, que só pode ser compreendida como um processo de permanentes avanços e recuos, que não está garantida para sempre. Nesse sentido, adverte Lima:

Exigirá processos permanentes de consolidação e de aprofundamento e esses não são possíveis à margem de práticas democráticas e participativas, do exercício de uma cidadania ativa e responsável, da velha virtude da coragem cívica de que já falavam os autores clássicos das teorias democráticas, ou seja, contra a passividade, o desinteresse, a alienação, a indecisão (LIMA, 2018, p. 246).

A ausência desses pré-requisitos essenciais ao exercício radical da democracia pode contribuir para o surgimento de movimentos reacionários que promovem constantes ataques ao mínimo de democracia vigente, incluindo-se as instituições educativas. A democracia (liberal) é aqui entendida como a materialização de direitos via políticas públicas (WOOD, 2003) coletivamente construídas (VIEIRA, 2007).

Em Mato Grosso, como resultado da mobilização da sociedade e da luta de trabalhadores/as da educação, além de ser dispositivo da Constituição Estadual, a Gestão Democrática foi garantida no Sistema Estadual de Ensino (LC n ${ }^{\circ}$ 049/98) e na Escola Pública (Lei no 7.040/98), com eleição do/a diretor/a e do Conselho Deliberativo da Comunidade Escolar (CDCE) e autonomia pedagógica, administrativa e financeira da escola; por meio da Lei ${ }^{\circ} 9.241 / 2009$, garantiuse a escolha, em eleições diretas, dos assessores pedagógicos, em consonância com os objetivos e metas definidos no Plano Estadual de Educação do Estado de Mato Grosso (Lei n ${ }^{\circ} 8.806$, de 10 de janeiro de 2008).

As primeiras tentativas para formalizar alterações na Lei $n^{0} 7.040 / 1998$, que regulamenta a gestão democrática das escolas públicas no estado, foram feitas por meio de portarias e da instituição de comissão técnica para reformular a Lei. O artigo primeiro dessa lei estabelece que a gestão democrática obedecerá aos seguintes princípios: 
I- corresponsabilidade entre Poder Público e sociedade na gestão da escola; II- autonomia pedagógica, administrativa e financeira da escola, mediante organização e funcionamento dos Conselhos Deliberativos da Comunidade Escolar, rigor na aplicação dos critérios democráticos para escolha do diretor de escola e transferência automática e sistemática de recursos às unidades escolares;

III- transparência dos mecanismos administrativos, financeiros e pedagógicos;

IV- eficiência no uso dos recursos financeiros (MATO GROSSO, 1998).

De acordo com o título V da Lei da Gestão Democrática, os diretores das unidades escolares serão escolhidos democraticamente pela comunidade escolar. No entanto, desde 2016, esse preceito é desrespeitado pelo governo de Mato Grosso, que não realiza eleições de diretores e de demais funções eletivas nas escolas estaduais, além de utilizar-se o expediente da prorrogação dos mandatos dos diretores e assessores pedagógicos, assim como dos membros dos Conselhos Deliberativos da Comunidade Escolar, até dezembro de 2018, como prevê a Portaria $n^{\circ} 428 / 2016 / G S / S E D U C / M T$. Por meio da Portaria ${ }^{\circ}$ 548/2017/GS/SEDUC/MT, prorrogou-se também, até 31 de dezembro de 2018, o mandato dos coordenadores pedagógicos das unidades escolares, efetivos e eleitos, designados e indicados.

Esses processos, que afrontam a Lei de Gestão Democrática, não ocorreram sem questionamentos por parte do Sindicato dos Trabalhadores no Ensino Público de Mato Grosso (SINTEP) e de diversas escolas, que exigiam eleições. Porém, a SEDUC não se sensibilizou com essas justas reivindicações. Muito pelo contrário, instituiu uma comissão técnica, por meio da Portaria n ${ }^{\circ}$ 182/2016/ GS/SEDUC/MT-SEDUC, para revisar e atualizar a Lei de Gestão Democrática e determinar critérios para escolha dos assessores pedagógicos, indicando de antemão, uma resistência a esse preceito legal e princípio democrático. Essa comissão produziu uma proposta, que foi rejeitada nas Conferências da Gestão Democrática, instituídas por meio da Portaria $n^{\circ}$ 456/2017/GS/SEDUC/MT, realizadas nos diversos municípios e polos do estado entre 06 de março e 15 de junho de 2018.

Os ataques à gestão democrática não se encerram no que fora apresentado, ainda estão por analisar as propostas de alterações à Lei no 7.040/1998, os resultados das Conferências realizadas em municípios e cidades de cada polo regional, as motivações da desistência da SEDUC de realizar a II Conferência de Gestão Democrática do Ensino Estadual (II CONGED), que ocorreria em 
21 e 22 de junho de 2018 em Cuiabá, assim como o cancelamento de eleições para Assessoria Pedagógica ${ }^{17}$ no município de Cáceres (MT).

Não tardaria e os impactos negativos das alterações na Lei de Gestão Democrática se evidenciariam em diversas instâncias do Sistema Estadual de Educação de Mato Grosso. Cabe recordar que, mesmo após a prisão do primeiro Secretário de Estado da Educação da gestão Pedro Taques (PSDB), Permínio Pinto, acusado de fazer parte de um esquema de corrupção na SEDUC, desviando aproximadamente 56 milhões de reais da educação para quitar dívidas de campanha do referido governador, o Secretário que o substituiu, com a mesma postura autoritária do governador, materializou inúmeras iniciativas de desrespeito ao princípio constitucional da gestão democrática com a prorrogação de todos os cargos eletivos na rede.

Essas medidas possibilitaram a destituição de cargos e indicação de outros, sem o prévio consentimento dos sujeitos escolares da comunidade por meio de eleições diretas. A cidade de Cáceres, situada a $220 \mathrm{~km}$ da capital Cuiabá, pode ser um exemplo de como a política de coerção da Secretaria de Estado da Educação gerou instabilidade e muitos conflitos nas escolas da rede pública estadual, destacando-se uma, em razão de posturas autoritárias e arbitrárias de interventores indicados pela SEDUC para a direção escolar e Assessoria Pedagógica no município. Neste último caso, os pais e alunos decretaram greve, com paralisação de aproximadamente 20 dias até que nova eleição ocorresse na escola, inclusive com reclamação junto ao Ministério Público Estadual (MPE), exigindo o restabelecimento de eleições. A situação foi resolvida após muita luta da comunidade escolar e sem a atuação incisiva do Ministério Público Estadual na exigibilidade do direito à gestão democrática, já que a manifestação desse órgão se deu somente no sentido de exigir da SEDUC providências para o retorno das aulas, com vistas ao cumprimento da carga horária e dias letivos a que o aluno tem direito.

Em razão de supostas irregularidades na gestão financeira de recursos da Merenda Escolar de duas escolas da rede, também no referido município, dois diretores e dois Assessores Pedagógicos foram afastados de suas funções e estão aguardando o andamento das investigações, como expresso nos Procedimentos Preparatórios $n^{\circ} 1.20 .001 .000017 / 2018-46$ e $n^{\circ} 1.20 .001 .000028 / 2018-26$ do

17 Os assessores pedagógicos do município de Cáceres (MT) legalmente eleitos e com seus mandatos prorrogados pela SEDUC em 2016 encontram-se afastados de suas funções desde abril de 2018, pela SEDUC, em razão de investigação e instauração de inquérito pelo Ministério Público Federal e pela Polícia Federal, respectivamente, mesmo antes de instaurar uma sindicância para apurar o envolvimento ou negligência com relação a uma suposta irregularidade na compra de merenda de duas escolas da rede pública estadual, sob a responsabilidade da Assessoria de Cáceres (JORNAL OESTE, 2018). 
Ministério Público Federal (MPF), que, inclusive, recomenda cancelamento de edital em andamento para eleições de Assessor Pedagógico no município, sob a alegação de que a eleição poderia prejudicar o desenrolar das investigações. A Secretária de Estado da Educação que assumiu a pasta em 2018 em substituição ao advogado Marco Aurélio Marrafon (PPS), afastado em 06 de abril de 2018 para concorrer ao legislativo federal, teria liberdade para não acatar tal recomendação, no entanto, atendeu prontamente ao MPF, inclusive baixando a Portaria $n^{\circ}$ 533/2018/GS/SEDUC/MT, que constitui uma Comissão de Assessores Técnicos da SEDUC para proceder a ações de apoio, monitoramento in loco e orientação à gestão de processos escolares nas 16 escolas da rede pública estadual localizadas no município de Cáceres, ou seja, a atuação de gestores escolares de todas as escolas da rede pública estadual do município e dos assessores pedagógicos foi colocada sob suspeita.

\section{Considerações finais}

Neste texto, voltamos o olhar para as ações ainda em curso, mesmo cientes dos riscos e limitações impostas. Como profissionais e pesquisadores da área educacional, temos um compromisso ético, político e social que nos impele também à denúncia da realidade. Muitos elementos abordados no presente texto poderão futuramente serem refutados, confirmados ou mesmo se tornarem objeto de outras investigações - esta é a vantagem da dinâmica do tempo. O tempo presente condiciona-nos a esta dinâmica e, quiçá, estejamos equivocados com nossas análises e que, em um futuro próximo, a correlação de forças entre classes e frações de classes penda para o desenvolvimento de avanços democráticos e para consistência de uma cidadania que imponha um freio à voracidade destrutiva dos mercados, como assinala Boron (2003), sobre o papel predatório do capitalismo neoliberal na América Latina.

Há sérios indícios de implicações das alterações legislativas da gestão democrática no sistema de ensino e na escola pública para a formação de sujeitos democráticos e participativos. Primeiro, pelo cerceamento do direito de eleger os representantes escolares; depois, porque se instaurou nas escolas um clima de tensão, proporcionado pela atuação e, inclusive, presença do MPF em reuniões de gestores e nas escolas. Com a SEDUC sob suspeita desde o início do Governo de José Pedro Taques (PSDB) - 2015 a 2018, parece que restou para ela simplesmente acatar decisões de instâncias federais, sem o devido questionamento. Não somos contrários à apuração de irregularidades na aplicação de 
recursos financeiros públicos e no cumprimento de carga horária e dias letivos, ou seja, na exigibilidade do direito ao acesso à educação. Entretanto, no contexto atual da sociedade brasileira, onde a mídia tem substituído a Ciência Política e outras importantes áreas do conhecimento no debate público sobre política e política educacional, vemos com reserva o protagonismo de certos atores do poder público, cuja atuação toma dimensão midiática, de espetaculização, afetando reputações sem probabilidade de reversão, caso os indivíduos sejam considerados inocentes.

Frente ao exposto, concluímos com Lima (2014) que estamos caminhando para uma pós-democracia gestionária, sob influência da Nova Gestão Pública (NPM) e das suas orientações gerencialistas em substituição à gestão democrática e suas potencialidades na construção da escola democrática. A perspectiva pósdemocrática vem se impondo sob o discurso que desqualifica a escola pública, ao focalizar, especialmente, os resultados nos testes e no Índice de Desenvolvimento da Educação Básica (Ideb), vistos hegemonicamente como sinônimos de qualidade. Tal discurso escamoteia a realidade social e educacional, marcada por intensas desigualdades, cujas consequências no desempenho de estudantes precisam ser consideradas. Porém, é sobre os resultados que os reformadores empresariais atuam na área educacional por meio de organizações sociais e fundações: agem como capitalistas, visam à obtenção de lucro com isenções fiscais, apropriam-se de fundos públicos e gerem a definição de conteúdo da educação, levando irremediavelmente à sua privatização e por privatização entendemos com Adrião (2015) "[...] o movimento que tem direcionado a educação básica PÚBLICA brasileira para o campo e sob o interesse do setor privado corporativo, lucrativo ou não, ou a este associado [...]." (ADRIÃO, 2015 , p. 7-8, grifos da autora).

\section{REFERÊNCIAS}

ADRIÃO, Theresa. Dimensões da educação básica no Brasil a partir de 1990: um diálogo com a produção acadêmica. Tese (Tese de livre docência) - Universidade Estadual de Campinas. Campinas, 2015.

AGÊNCIA DA NOTÍCIA. Sindicalista afirma que discurso do Governo sobre PEC é "falácia". 16 de outubro de 2017. Disponível em: http://www.agenciadanoticia.com.br/ noticias/exibir.asp?id=64663\&noticia $=$ sindicalista-afirma-que-discurso-do-governosobre-pec-e-falacia. Acesso em: 05 set. 2018. 
AMARAL, Daniela Patti do. A gestão democrática das escolas como referencial político, educativo e simbólico: Entrevista com o professor Licínio Lima. Movimento: Revista de Educação. Ano 5, n. 8, UFF, 2018.

ANDES. Projeto Escola Sem Partido é arquivado e só volta a ser debatido em 2019. 07 de janeiro de 2019. Disponível em: https://www.andes.org.br/conteudos/noticia/ projeto-escola-sem-partido-e-arquivado-e-so-volta-a-ser-debatido-em-20190. Acesso em: 23 set. 2019.

BECK, Ulrich. Sociedade de risco mundial: em busca da segurança perdida. Tradução: Marian Toldy e Teresa Toldy. Lisboa, Portugal: Almedina, 2015.

BORON, Atílio. Después del saqueo: el Capitalismo Latinoamericano a Comienzos del Nuevo Siglo. In: BORON, Atílio. Estado, Capitalismo y Democracia em América Latina. 1 ed. Buenos Aires: Clacso, 2003, p. 15-38.

BRAIT, Daniele. Os protagonistas do Escola Sem Partido (ESP). In: Ação Educativa, Pesquisa e Informação (Org.). São Paulo: Ação Educativa, 2016.

BRASIL. Constituição da República Federativa do Brasil de 1988. Disponível em: http:// www.planalto.gov.br/ccivil_03/Constituicao/Constituicao.htm. Acesso em: 11 set. 2018.

. Lei n. 13.005, de 25 de junho de 2014. Aprova o Plano Nacional de Educação - PNE e dá outras providências. Disponível em: http://www.planalto.gov.br/ccivil_03/_ ato2011-2014/2014/lei/113005.htm. Acesso em 23 de set. 2019.

. Emenda Constitucional n. 95, de 15 de dezembro de 2016. Altera o Ato das Disposições Constitucionais Transitórias, para instituir o Novo Regime Fiscal, e dá outras providências Disponível em: https:/www2.camara.leg.br/legin/fed/emecon/2016/ emendaconstitucional-95-15-dezembro-2016-784029-publicacaooriginal-151558-pl. html. Acesso em: 12 set. 2018.

. CPI da Previdência aprova relatório final. Senado Federal. 2017. Disponível em: https:/www12.senado.leg.br/noticias/materias/2017/10/25/cpi-da-previdenciaaprova-relatorio-final-por-unanimidade. Acesso em: 11 set. 2018.

. Relatório do $2^{\circ}$ Ciclo de Monitoramento das Metas do Plano Nacional de Educação 2018. Disponível em: http://portal.inep.gov.br/documents/186968/485745/ RELAT \%C3\%93RIO+DO+SEGUNDO+CICLO+DE+MONITORAMENTO+DAS +METAS+DO+PNE+2018/9a039877-34a5-4e6a-bcfd-ce93936d7e60?version=1.17. Acesso em: 12 set. 2018.

BRESSER PEREIRA, Luiz C. Do antigo ao novo desenvolvimentismo na América Latina, 2010. Disponível em: http://www.bresserpereira.org.br/papers/2010/10.01. Do_velho_novo_desenvolvimentismo.CCF.pdf. Acesso em: 14 ag. 2016.

CHOMSKY, Noam. Chomsky: O Brasil está sofrendo um golpe brando. 18 de maio de 2016. Disponível em: https://blogdaboitempo.com.br/2016/05/18/chomsky-o-brasil-estasofrendo-um-golpe-brando. Acesso em: 10 set. 2017. 
ESCOBAR, Pepe. Brasil no epicentro da guerra híbrida. Tradução: Vinícius Gomes Melo e Inês Castilho. Disponível em: https://outraspalavras.net/brasil/o-brasil-no-epicentroda-guerra-hibrida. 2016. Acesso em: 10 set. 2018.

FOREQUE, Flávia; CRUZ, Valdo; VERSIANI, Isabel. Educação e Saúde terão novo corte em orçamento; PAC será principal alvo. Folha de São Paulo, São Paulo, 30 julho 2015. Caderno Mercado. Disponível em: https:/www.ufpe.br/documents/40070/1837975/ ABNT+NBR+6023+2018+\%281\%29.pdf/3021f721-5be8-4e6d-951b-fa354dc490ed. Acesso em: 26 de ago. 2019.

GAZETA DO POVO. Rebaixamento mostra equívocos e desacertos do governo Dilma, diz Aécio. 24 março 2014. Disponível em: https://www.gazetadopovo.com.br/vidapublica/rebaixamento-mostra-equivocos-e-desacertos-do-governo-dilma-diz-aecio21u0m8ei425rk194g3oiixhzi/. Acesso em 7 dez. 2015.

JINKINGS, Ivana; DORIA, Kim; CLETO, Murilo (Orgs.). Porque gritamos golpe? Para entender o impeachment e a crise política no Brasil. São Paulo: Boitempo Editorial, 2016.

JORNAL OESTE. 'Malandragem'de diretores de escolas estaduais derruba assessores pedagógicos em Cáceres. Educação. 09 abril 2018. Disponível em: http://www.jornaloeste.com.br/noticias/exibir.asp?id=44621\&noticia=malandragem_de_diretores_de_escolas_estaduais_derruba_assessores_pedagogicos_em_caceres. Acesso em 06 de set. 2018.

KORYBKO, Andre. O Brasil é alvo da guerra híbrida, afirma analista. Entrevista feita por Eleonora Lucena e Rodolfo Lucena, em 20 de dezembro de 2018. Disponível em: http://www.vermelho.org.br/noticia/316228-1. Acesso em: 23 dez. 2018.

LIMA, Licínio. In: AMARAL, Daniela Patti do. A gestão democrática das escolas como referencial político, educativo e simbólico: Entrevista com o professor. Revista de Educação. Ano 5, n. 8, Universidade Federal Fluminense, 2018.

. A gestão democrática das escolas: do autogoverno à ascensão de uma pós-democracia gestionária? Educação e Sociedade, Campinas, v. 35, n. 129, p. 1067-1083, out.-dez., 2014.

MATO GROSSO. Lei 7.040, de $1^{\circ}$ de outubro de 1998. Lei da gestão democrática. Diretrizes Educacionais. Estado de Mato Mato Grosso. Secretaria de Estado de Educação. Cuiabá: Central de Texto, 1998.

. PEC 10/2017 que limita teto dos gastos. 2017. Disponível em: https://www.al.mt. gov.br/midia/texto/promulgada-a-emenda-constitucional-que-limita-os-gastos-publicos/ visualizar. Acesso em: 04 set. 2018.

MIGUEL, Luis Felipe. Dominação e resistência: desafios para uma política emancipatória. 1. ed. São Paulo: Boitempo, 2018.

PARTIDO DO MOVIMENTO DEMOCRÁTICO BRASILEIRO. Uma ponte para o futuro. Brasília: Fundação Ulysses Guimarães, 2015. Disponível em: https:/www.fundacaoulysses.org.br/wp-content/uploads/2016/11/UMA-PONTE-PARA-O-FUTURO. pdf. Acesso em: 26 set. 2019. 
PINTO, José Marcelino de Rezende. O financiamento da educação na Constituição Federal de 1988: 30 anos de mobilização social. Educação e Sociedade, Campinas, v. 39, n. 145, out.-dez., 2018. Disponível em: http:/www.scielo.br/pdf/es/v39n145/16784626-es-es0101-73302018203235.pdf. Acesso em: 11 fev. 2019.

PT. Há 16 anos, Lula lançava a “Carta ao Povo Brasileiro”. 2018. Disponível em: https:// pt.org.br/ha-16-anos-lula-lancava-a-carta-ao-povo-brasileiro/. Acesso 23 de set. 2019.

RAMOS, Gustavo Teixeira; FILHO, Hugo Cavalcanti Melo; LOGUERCIO, José Eymard; FILHO, Wilson Ramos. A Classe Trabalhadora e a Resistência ao Golpe de 2016. Bauru: Canal 6, 2016.

REPÓRTER MT. Isenção de impostos ao agronegócio faz MT perder R\$39 milhões por ano. Cuiabá, 29 maio 2017. Disponível em: https://www.reportermt.com.br/poderes/ isencao-de-impostos-ao-agronegocio-faz-mt-perder-r-39-bilhoes-por-ano/68096. Acesso em: 5 de set. 2018.

SALVADOR, Evilasio. Perfil da Desigualdade e da Injustiça Tributária com Base nos declarantes do Imposto de Renda no Brasil 2007-2013. Instituto de Estudos Socioeconômicos. Brasília, 2016.

SANTOS, Boaventura de Sousa. Reinventar a democracia. Fundação Mário Soares. Gradiva Publicações. Lisboa (Portugal), 2002.

SENADO NOTÍCIAS. Dilma Rousseff perde mandato e Temer é confirmado presidente. Brasília, 31 agosto 2016. Disponível em: https://www12.senado.leg.br/noticias/ materias/2016/08/31/dilma-rousseff-perde-o-mandato-e-temer-e-confirmado-presidente. Acesso em 26 de set. 2019.

SOUZA, Jessé. A Elite do Atraso: da escravidão à Lava Jato. Rio de Janeiro: Leya, 2017.

STREECK, Wolfgang. As crises do Capitalismo Democrático. Dossiê Crise Global: Novos Estudos, n. 92, 2012. Disponível em: http://www.scielo.br/pdf/nec/n92/n92a04. pdf. Acesso em: 02 ago. 2018.

VIEIRA, Evaldo. Os direitos e a política social. 2. ed. São Paulo: Cortez, 2007.

WOOD, Ellen M. Democracia contra o Capitalismo: a renovação do materialismo histórico. Trad. Paulo Cesar Castanheira. São Paulo, Boitempo, 2003.

. Estado, democracia e globalização. In: BORON, Atílio; AMADEO, Javier; GONZÀLES, Sabrina. (Orgs.). 1 ed. Buenos Aires. CLACSO, 2006, p. 381-394.

Texto recebido em 28/09/2019

Texto aprovado em $01 / 11 / 2019$. 